MiW program. Our study demonstrates that self-management programs, including group meetings, can be successfully delivered using an online format, which facilitates wider dissemination, with greater convenience to patients, and at lower costs.

Disclosure of Interest: None declared

DOI: 10.1136/annrheumdis-2017-eular.5246

\section{THU0616 PATIENTS' PERCEPTION ON DISEASE PROGRESSION AND ADHERENCE TO BIOLOGIC THERAPY}

E. Cefai, D. Balzan, C. Mercieca, A.A. Borg. Rheumatology, Mater Dei Hospital, Msida, Malta

Background: Adherence to medication depends on several factors such as medication beliefs, psychosocial factors, illness beliefs and concerns. The consequences of non-adherence are not insignificant, both from the clinical and health economic aspects.

Objectives: To assess medication adherence of patients taking biologics who are in remission or who have low disease activity and patients' perception of disease progression.

Methods: Forty-four consecutive patients attending a dedicated biologic clinic and treated with TNF inhibitors were interviewed following their visit. Patients were asked about adherence to treatment, adverse effects, concerns about biologics and their perception of disease progression. Demographic and disease activity data were recorded.

Results: Forty-four patients (23 females, 21 males) participated in the survey (21 suffered from rheumatoid arthritis, 17 from ankylosing spondylitis and 6 from psoriatic arthritis). The mean age was 55.1 (SD 12.62) years. The mean DAS28 was 2.26 (SD 1.03) and the mean BASDAI was 4.21 (SD 2.1). Minimal or no pain was reported by $75 \%$, mild or no fatigue by $78 \%$ and $77 \%$ had no restriction of activities of daily living. Medication adherence was reported as high by $68 \%$ and moderate by $32 \%$. There were no patients who had a low level of adherence. $5 \%$ of patients admitted to be unaware of the need to omit their biologic when ill and $40 \%$ when requiring surgery.

One out of 4 patients reported to have experienced adverse events, most commonly infections. $19 \%$ claimed to be moderately or very concerned about the adverse effects. On further questioning about the severity of potential adverse effects, $45 \%$ were unsure as to what the severity might be. When asked about duration of therapy, $29 \%$ replied more than 10 years; whilst $71 \%$ were unsure on when, if ever, the biologic is going to be stopped. Patients were also asked whether they believed that the biologic had successfully stopped further joint damage and $68 \%$ replied yes, $9 \%$ replied no, whilst $23 \%$ were unsure. Of those who replied yes, this perception was based on the absence or reduction of symptoms.

Conclusions: In this cohort of patients with low disease activity or remission, a third of patients still reported sub-optimal adherence to TNF inhibitor use. The benefits of adherence to biologic therapies need to be reinforced at every visit and factors leading to non-adherence addressed. Adverse effects remain a major concern that needs to be addressed, even in patients who have been on biologics for many years and have sustained remission or low disease activity. A quarter of patients were unsure whether biologics have stopped joint damage. Patients' perception of joint damage progression needs to be explored to find ways of making it more understandable to patients.

Disclosure of Interest: None declared

DOI: 10.1136/annrheumdis-2017-eular.3221

\section{THU0617 INFORMATION ON DISEASE AND TREATMENT OF PATIENTS WITH RHEUMATIC DISEASES TREATED WITH SUBCUTANEOUS BIOLOGICALS: SOURCES AND SATISFACTION. RHEU-LIFE SURVEY}

F. de Toro ${ }^{1}$, E. Batlle ${ }^{2}$, C. González ${ }^{3}$, M. Calvo ${ }^{4}$, M. Arteaga $^{4}$, L. Cea-Calvo ${ }^{4}$. ${ }^{1}$ INBIC, A Coruña; ${ }^{2}$ D.Salud Sant Joan, Alicante; ${ }^{3}$ H.G.U.Gregorio Marañón; ${ }^{4}$ Medical Affairs, Merck Sharp \& Dohme, Madrid, Spain

Objectives: To know the sources by which patients with rheumatic diseases treated with subcutaneous (SC) biological drugs obtain information on their treatment, their satisfaction with the information received from the hospital staff and their perception of the degree of information they have.

Methods: RHEU-LIFE was a survey handed by 50 rheumatologists from Spanish outpatients hospital offices to patients on SC biological drugs. They completed the survey anonymously at home and returned it by pre-paid post-mail. They selected from a list their sources of information (being able to mark all their sources), their satisfaction with the information received from the hospital staff and whether they had sought additional information in other sources.

Results: The survey was handed to 1000 patients and 592 returned it $(59.2 \%$, mean age 51.7 years, $57.6 \%$ women). The source of information most frequently mentioned was the rheumatologist (table) and, infrequently, the nurse or the hospital pharmacist. $46.1 \%$ had received information on the SC biological only orally, $6.0 \%$ written and $45.2 \%$ in both ways. The percentages quite or very satisfied with the information received were $42.6 \%$ and $44.5 \%$ respectively, $10.6 \%$ felt "neither satisfied nor dissatisfied" and $2.1 \%$ and $0.2 \%$ dissatisfied or very dissatisfied. The \% quite/very satisfied was higher when the information came from the rheumatologist $(89.6 \%$ vs $59.6 \%$ when the rheumatologist was not mentioned as source of information, $p<0.001$ ), and also when information was given both oral and written $(92.8 \%$ vs $86.1 \%$ if only oral information was given, $\mathrm{p}=0.0125)$. Some $45.2 \%$ had sought information on the SC biological in sources different to the hospital staff, the \% being higher among younger patients ( $<43$ years: $65.2 \%$ : 43-52 years: $51.4 \%, 53-61$ years: $39.1 \%,>61$ years: $20.6 \%, p<0.001)$ those with higher education level (without studies: $14.3 \%$, primary: $31.6 \%$, secondary: $55.6 \%$, vocational: $59.5 \%$, university or higher degrees: $64.9 \%, p<0.001$ ), and in those treated with a first biological SC drug $(49.9 \%$, vs. $37.7 \%$ and $37.2 \%$ with a second or third or further, $\mathrm{p}=0.014)$.

Sources from which patients received information on the different treatments and on the biological drug (patients could mark more than one option)

\begin{tabular}{lcc}
\hline & General information & Information on the SC biological \\
\hline Rheumatologist & $91.9 \%$ & $91.0 \%$ \\
Nurse & $10.2 \%$ & $17.9 \%$ \\
Hospital pharmacist & $3.2 \%$ & $11.5 \%$ \\
Other & $5.3 \%$ & $3.6 \%$ \\
Do not remember & $1.2 \%$ & $0.8 \%$ \\
Did not receive any information & $0.8 \%$ & $1.7 \%$ \\
\hline
\end{tabular}

Conclusions: Patients with rheumatic diseases mention the rheumatologist as their main source of information. The \% who mentioned nurses or pharmacists was low, although the latter are very frequently visited for dispensing the drug. Satisfaction with the information received was high, but clearly lower when the rheumatologist did not inform the patient. Nearly half reported having sought information in sources other than the hospital staff.

Acknowledgements: Endorsed by ConArtritis (National Coordinator of Patients with Arthritis). Funded by Merck Sharp \& Dohme of Spain

Disclosure of Interest: None declared

DOI: 10.1136/annrheumdis-2017-eular.3214

\section{THU0618 THE FACTORS AFFECTING WORKPLACE AND HOUSEHOLD LIFE IN ANKYLOSING SPONDYLITIS: A MULTI-DIMENSIONAL STUDY}

B. Taser ${ }^{1}$, F.F. Ayhan ${ }^{1,2}$, P. Borman ${ }^{1,3}$, A. Karagöz ${ }^{1} .{ }^{1}$ Physical medicine \& rehabilitation, Ankara Training and Research Hospital, Ankara; ${ }^{2}$ Physical therapy \& rehabilitation, Uşak University, School of Health Sciences, Uşak; ${ }^{3}$ Physical medicine \& rehabilitation, Hacettepe Medical School, Ankara, Turkey

Background: Work disability (WD) is the final stage of work problems and may be prevented by effective treatment and ergonomic interventions in earlier stage of work productivity loss and work instability. Contextual factors, disease related factors and local social security systems may also affect WD.

Objectives: We aimed to determine the predictive factors of work productivity and work stability in Turkish patients with ankylosing spondylitis

Methods: One-hundred patients with ankylosing spondylitis (31 females and 69 males) were included into this study. Demographics, working state, Bath scores of disease activity, functional and radiologic state, quality of life, cardiopulmonary functions (echocardiography, exercise stress test and pulmonary function test) and general work impairments (work productivity impairment and work instability) were recorded. WPAI and AS-WIS were selected as work outcomes. The most predictive factors were analyzed in work productivity and work instability. SPSS 14.0 statistics (descriptives, pearson correlation, and stepwise regressions were used for statistical analyses.

Results: Thirty-two patients (mean age: 42,6 \pm 11.7 ) were unemployed. Unemployed patients showed more female, less educated, low disease activity, and low fitness profile. The percentages of absenteeism (WPAl-1), presenteeism (WPAI-2), regular activity impairment (WPAI-3) and overall work impairment (WPAI-4) were determined as $8,44, \% 47$, and $\% 37$, respectively, in employee group. When affecting factors assessed with multiple stepwise linear regression analysed; the only determinant for absenteeism (WPAI-1) was the working day loss due to ilness at last year. Chest mobility, annual income level, AS quality of life (ASQLL), work change and co-morbid diseases were the determinants of presenteeism (WPAI-2), regular activity impairment (WPAI-3) and overall work impairment (WPAI-4). The score of mean work instability (AS-WIS) was $11.5 \pm 5.8$, and $42.6 \%$ of patients had low and $57,4 \%$ of patients had moderate-high work instability. Multiple stepwise linear regression analysis showed that most predictive factors for work instability were regular activity impairment (WPAI-3) and AS-QoL. The factors affecting non-work status were older age, female sex and low annual income level in stepwise logistic regression.

Conclusions: The common predictive factor of work productivity and work stability was quality of life. For evaluation of work productivity; socioeconomic factors such as annual income level and frequent work change were determinative as well as clinical datas (chest expansion and comorbid diseases). We suggested both pharmacologic and nonpharmacologic interventions to improve quality of life should be enabled in early period to improve work productivity.

Disclosure of Interest: None declared

DOI: 10.1136/annrheumdis-2017-eular.2550 